\title{
Использование природных монтмориллонитовых глин в процессе коагуляционной очистки сточных вод прачечных
}

\author{
(C) 2020 Отырба Г.Г., Фидченко М.М., Каменчук И.Н., \\ Клушин В.Н., Курилкин А.А.
}

Российский химико-технологический университет им. Д. И. Менделеева, Москва

Поступила в редакцию 07.10 .2020 г.

DOI: $10.17308 /$ sorpchrom.2020.20/3057

Для очистки сточных вод от поверхностно-активных веществ (ПАВ) используют различные методы, например, электрофлотокоагуляцию и тот же метод, дополненный нанофильтрацией. Авторами работы было предложено использовать сочетание адсорбции и коагуляции с добавками небольших доз флокулянтов для обеспечения хорошего эффекта очистки от ПАВ и взвешенных веществ и снижения затрат.

Для опытов использовали природную монтмориллонитовую глину Асканского месторождения (Грузия). Модельный раствор стоков прачечных содержал 1 г/дм³ как анионных, так и неионогенных ПАВ. В качестве имитатора мутности в модельный раствор вносили белый каолин $(0.2$ г/дм³). Органические примеси моделировали дополнительным введением сахара (100 мг/дм³). Показано, что для достижения высокой степени очистки исследуемых стоков с помощью глины требуется длительный период контакта фаз и высокие дозы адсорбента. В следующей серии опытов в модельный раствор добавляли коагулянт - раствор $\mathrm{FeCl}_{2}$, флокулянт и глину в количестве 2 г/дм³. Добавка глины играла не только роль эффективного адсорбента, но и утяжелителя осадка коагулянта.

Эффективность коагуляционной очистки в сочетании с использованием глины оценивали по остаточной концентрации общего и органического углерода (ООУ) очищенного раствора, ХПК очищенного модельного раствора, сухого и прокаленного остатка, содержание взвешенных веществ и остаточной концентрации общего железа, а также величине рН исходного и очищенного растворов.

При сравнении применения сухой бентонитовой глины и её 10\%-ной суспензии в воде установлено, что при добавлении сухой глины укрупнение осадка и осветление жидкой фазы происходит с большей скоростью, а также очистка от органических примесей достигает 56 отн. \%, а взвешенных веществ - 90 отн. \%.

На основании проведенных исследований можно сделать вывод об успешности проведения коагуляции с добавками Асканской бентонитовой глины для предварительной очистки стоков прачечных с возможностью утилизации образующегося осадка без промежуточной сушки в технологии углеродминеральных адсорбентов-катализаторов.

Ключевые слова: очистка воды от органических примесей, коагуляция, взвешенные вещества, поверхностно-активные вещества, стоки прачечных, бентонитовая глина.

\section{Введение}

В настоящее время остро стоит вопрос об очистке сточных вод крупных городских прачечных. Хотя доля стоков прачечных, загрязненных, в частности, разнообразными поверхностно-активными веществами (ПАВ), составляет менее $1 \%$, но именно они являются объектом для проверок государственными экологическими службами. Сточные воды прачечного предприятия содержат, как правило, взвешенные частицы (так называемую эмульгированную грязь), соли жесткости, механические загрязнения 
в виде частиц пыли и волокон ткани, красители, нефтепродукты, а также наиболее опасные примеси ПАВ - анионных (АПАВ) и неионогенных (НПАВ) [1].

В промышленности сточные воды, содержащие ПАВ, очищают перед сбросом, но при бытовом использовании этих веществ загрязненные стоки сразу сбрасывают в городскую канализацию. Но даже маленькие концентрации ПАВ при попадании в природные водоемы могут оказывать негативное влияние на живые организмы в водоеме из-за нарушения его кислородного обмена. Необходимость очистки сточных вод от ПАВ очевидна и необходима. Для достижения этой цели используют различные методы, например, электрофлотокоагуляции (ЭФ) [2] и тот же метод, дополненный нанофильтрацией (НФ) [3].

В последней работе представлены состав сточных вод прачечного предприятия и химпроизводства моющих средств, а также результаты очистки сточных вод комбинированным методом электрофлотации и нанофильтрации (табл. 1). Авторы показали, что содержание ПАВ в сточных водах при производстве моющих средств гораздо выше (АПАВ - 700 мг/дм ${ }^{3}$; НПАВ - 100 мг/дм ${ }^{3}$ ) по сравнению со стоками типового прачечного предприятия (АПАВ - 3 мг/дм³ $;$ НПАВ - 10 мг/дм³).

Таблица 1. Результаты очистки сточных вод прачечных предприятий и производств моющих средств (I - сточные воды типового прачечного предприятия, II - сточные воды типового производства моющих средств)

Table 1. Results of the purification of laundry wastewater and detergents products

\begin{tabular}{|c|c|c|c|c|c|c|c|}
\hline \multirow[b]{2}{*}{ Показатель } & \multicolumn{7}{|c|}{ Концентрация, мг/дм ${ }^{3}$} \\
\hline & $\begin{array}{l}\text { Сточ- } \\
\text { ные } \\
\text { воды I }\end{array}$ & $\begin{array}{l}\text { Сточ- } \\
\text { ные } \\
\text { воды II }\end{array}$ & $\begin{array}{c}\text { После } \\
\text { ЭФ }\end{array}$ & $\begin{array}{c}\text { После } \\
\text { НФ }\end{array}$ & $\begin{array}{c}\text { Питье- } \\
\text { вая } \\
\text { вода } \\
\text { СанПиН }\end{array}$ & $\begin{array}{l}\text { ПДК } \\
\text { МВК } \\
\text { (СПб) }\end{array}$ & $\begin{array}{c}\text { ПДК } \\
\text { РыбХоз }\end{array}$ \\
\hline $\mathrm{pH}$ & $7.5-8$ & $7-7.5$ & $7-8$ & $6.5-8.5$ & $6-9$ & $6.5-8.5$ & $6.5-8.5$ \\
\hline Железо, $\mathrm{Fe}^{3+}$ & $1-5$ & $1-5$ & 0.1 & $<0.04$ & 0.3 & 3 & 0.1 \\
\hline $\begin{array}{c}\text { Алюминий, } \\
\mathrm{Al}^{3+} \\
\end{array}$ & $5-20$ & $5-20$ & 0.2 & $<0.04$ & 1.5 & 1 & 0.04 \\
\hline $\begin{array}{c}\text { Взвешенные } \\
\text { вещества, } \\
\text { мг/дм³ }\end{array}$ & 1300 & 170 & $0.1-1$ & $<0.04$ & 1.5 & 500 & 0.25 \\
\hline $\begin{array}{c}\text { Фосфаты, } \\
\mathrm{PO}_{4}{ }^{3-}\end{array}$ & 2 & $<10$ & $<0.04$ & $<0.01$ & 3.5 & 4 & - \\
\hline Сухой остаток & 2000 & 2700 & & & 1000 & 2000 & - \\
\hline $\begin{array}{l}\text { Сульфаты, } \\
\mathrm{SO}_{4}^{2-}\end{array}$ & 10 & 50 & $10-50$ & $<0.2$ & 500 & 500 & 100 \\
\hline Хлориды, $\mathrm{Cl}^{-}$ & 250 & $<10$ & $<250$ & $<150$ & 350 & 350 & 300 \\
\hline $\begin{array}{c}\text { Эфироизвле- } \\
\text { кае мые } \\
\text { вещества, } \\
\text { мг/дм }{ }^{3} \\
\end{array}$ & 60 & отс. & $0.1-1$ & $<0.05$ & отс. & 20 & отс. \\
\hline Жиры, мг/дм ${ }^{3}$ & 60 & 10 & $0,1-1$ & $<0.05$ & отс. & 20 & 0.05 \\
\hline АПАВ, мг/дм ${ }^{3}$ & 3 & 700 & $1-350$ & $<2.5$ & 0.5 & 2.5 & 0.25 \\
\hline НПАВ, мг/дм ${ }^{3}$ & 10 & 100 & $5-50$ & $<0.2$ & отс. & - & отс. \\
\hline $\begin{array}{c}\text { Нефтепродукт } \\
\text { ы }\end{array}$ & 1 & 70 & $<0.5$ & $<0.05$ & 0.1 & 4 & 0.05 \\
\hline $\begin{array}{c}\text { ХПК, мг } \\
\text { О/дм } \\
\end{array}$ & 3300 & 7150 & $\begin{array}{l}1600- \\
3500\end{array}$ & $<800$ & $<15$ & 800 & 3 \\
\hline БПК, мгО ${ }_{2} /$ дм$^{3}$ & 500 & 1850 & $\begin{array}{c}250- \\
900 \\
\end{array}$ & $<500$ & $<15$ & 500 & 3 \\
\hline
\end{tabular}


Как следует из табл. 1 после первой стадии очистки - электрофлотации (ЭФ) количество ПАВ в растворе уменьшилось в два раза. В сточных водах прачечного предприятия остаточное содержание АПАВ составило 1 мг/дм ${ }^{3}$, а НПАВ - 5 мг/дм ${ }^{3}$ В сточных водах производства моющих средств содержание АПАВ снизилось до 350 мг/дм ${ }^{3}$, а НПАВ -до 50 мг/дм³ ${ }^{3}$ После второй стадии очистки - нанофильтрации (НФ) остаточное содержание ПАВ в сточных водах составило, соответственно, АПАВ $>2.5 \mathrm{мг} /$ дм $^{3}, \mathrm{HПАВ}>0.2 \mathrm{мг} /$ дм $^{3}$.

Таким образом, авторы статьи [4] поставили цель изучить в сравнении следующие методы очистки сточных вод выбранных источников от ПАВ: электролиз, коагуляцию, сорбцию и флотацию - и на основании исследований сделать вывод о перспективности применения того или иного метода. Воду на очистку подавали в реакционную камеру с металлическими электродами, на которых генерировались ионы металлов и образовывались их гидроксиды, а в результате электролиза воды генерировались водород и кислород. Образовавшийся в процессе флотации пенный продукт выводили в пеносборный карман, а очищенную воду направляли на отстаивание. Оптимальное время обработки составляло 20 минут при плотности тока $85 \mathrm{~A} / \mathrm{M}^{2}$.

Метод электрокоагуляции показал эффективность при очистке сточных вод, содержащих большое количество алкилсульфонатов, в щелочной среде при $\mathrm{pH}=11$ [5]. Процесс вели на электродах из алюминия и меди, для подщелачивания использовали негашеную известь. Для вод с концентрацией СПАВ (до 100 мг/дм³), по мнению авторов, следует использовать прямую электрокоагуляцию без добавления нейтрализующих средств.

В ряде случаев можно достигнуть хорошего эффекта очистки при использовании метода простой коагуляции сульфатами алюминия или железа [4]. Авторы использовали этот метод для очистки воды с низким содержанием АПАВ (1-20 мг/дм³), но посчитали его затратным из-за больших доз коагулянтов и необходимости переработки большого объема выпадающего осадка. Однако достигнутая степень очистки воды была высокой и составила порядка 90\%.

По нашему мнению, сочетание адсорбции и коагуляции с добавками небольших доз флокулянтов может также дать хороший эффект очистки от ПАВ и взвешенных веществ и сделать процесс менее затратным, если найти эффективный адсорбент и предложить достойное применение образующегося осадка.

Для подтверждения этого предположения провели исследование процесса очистки модельных стоков промышленных прачечных от ПАВ и других органических примесей и взвешенных веществ с использованием природной монтмориллонитовой глины. С одной стороны, она служила адсорбентом, а с другой стороны выполняла роль утяжелителя осадка коагулянта - хлористого железа.

\section{Экспериментальная часть}

Для опытов использовали природную монтмориллонитовую глину Асканского месторождения (Грузия). Модельный раствор стоков прачечных готовили с использованием стирального порошка марки Persil Expert (1 г/дм³), содержащего как анионные, так и неионогенные ПАВ. В качестве имитатора мутности в модельный раствор вносили белый каолин $(0.2$ г/дм³ $)$. Органические примеси моделировали дополнительным введением сахара $\left(100 \mathrm{мг} /\right.$ дм $\left.^{3}\right)$.

Постановку этих опытов мотивировали тем, что остаточные органические примеси в очищенной путем коагуляции воде могут быть в дальнейшем обезврежены 
окислительной деструкцией пероксидом водорода на адсорбенте-катализаторе в сочетании с биологической очисткой. Образовавшийся при коагуляции осадок влажной глины, загрязненный органикой и железом, предполагали использовать для производства углеродминерального катализатора, который может быть полезен для повышения эффективности ступени окисления в этом же процессе.

В серии предварительных опытов провели исследование влияния дозы Асканской глины на остаточную концентрацию органических примесей в исходном модельном растворе, которую оценивали по величине общего и органического углерода (ООУ). Дозу глины варьировали в интервале 2-8 г/дм³, объем пробы раствора составлял $100 \mathrm{~cm}^{3}$. Глину с раствором контактировали в течение 2 суток при периодическом перемешивании системы. Затем проводили отделение частиц глины путем центрифугирования в течение 10 минут при скорости вращения ротора центрифуги 3000 об/мин. Осветленную жидкость анализировали на содержание ООУ на газовом хроматографе ЛХМ-8МД.

В следующей серии опытов в модельный раствор добавляли коагулянт - раствор $\mathrm{FeCl}_{2}$, флокулянт и глину в количестве 2 г/дм³. Добавка глины играла не только роль эффективного адсорбента, но и утяжелителя осадка коагулянта. Она была необходима, т.к. присутствие в воде ПАВ затрудняло осаждение коагулянта, осадок гидроксида железа всплывал и при удалении с поверхности жидкости легко разрушался. В присутствии же глины происходило быстрое укрупнение частиц осадка, осветление жидкой фазы и осаждение образовавшихся частиц.

Эффективность коагуляционной очистки в сочетании с использованием глины оценивали по остаточной концентрации общего и органического углерода (OOУ) очищенного раствора. При достижении высоких степеней очистки воды дополнительно проверяли величины ХПК очищенного модельного раствора, сухого и прокаленного остатка, содержание взвешенных веществ и остаточной концентрации общего железа [6-8]. Кроме того, контролировали также величину $\mathrm{pH}$ исходного и очищенного растворов.

Основные характеристики исходного модельного раствора сточной воды прачечных: ХПК - 363 мг/дм³ $;$ pH - 9.8; содержание общего органического углерода 144 мг/дм³ ; содержание взвешенных веществ - 204 мг/дм³ ; величина сухого остатка 1297 мг/дм³ ; величина прокаленного остатка -883 мг/дм³

Процесс коагуляции проводили следующим образом: $250 \mathrm{~cm}^{3}$ исходного модельного раствора помещали в мерный цилиндр, вносили туда заданную навеску бентонитовой глины (2 г/дм $\left.{ }^{3}\right)$, суспензию перемешивали двухлопастной мешалкой в течение определенного промежутка времени (15-60 минут) при скорости вращения мешалки 120 об/мин, затем вносили в систему заданный объем раствора коагулянта $\left(100 \mathrm{мг} /\right.$ дм $\left.^{3} \mathrm{Fe}^{2+}\right)$, продолжая перемешивание еще в течение 2 минут. Потом, не останавливая процесс, добавляли заданную дозу раствора полиакриламидного флокулянта марки Sedipur NF-102 (1.5-2.0 мг/дм³). Через минуту после внесения флокулянта перемешивание прекращали и оставляли систему для разделения фаз. Через 5 минут отбирали пробу осветленной жидкости из верхней части цилиндра для определения содержания ООУ.

Поскольку время контакта раствора с глиной должно влиять на эффективность очистки (на содержание ООУ) исследовали процесс с различным временем перемешивания суспензии глины в очищаемой воде. Доза глины 2 г/дм ${ }^{3}$, доза $\mathrm{Fe}^{2+}=$

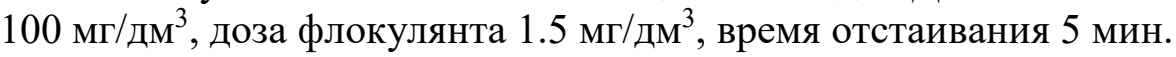

В связи с тем, что бентонитовые глины относятся к адсорбентам, способным расширять пористую структуру под действием воды, представляло интерес проверить влияние предварительного ее замачивания на эффективность последующей очистки. 
Для этого в процессе очистки использовали не только сухую глину, но и ее $10 \%$ суспензию в воде. Для получения эффекта набухания глины суспензию оставляли на сутки в воде, после чего необходимую ее дозу (2 г/дм³ глины в расчете на сухое вещество) добавляли к $250 \mathrm{~cm}^{3}$ исходного раствора. Далее проводили коагуляцию при тех же условиях, что и с сухой глиной. Эффект осветления системы наблюдали по изменению ее оптической плотности во времени при 670 нм в кювете фотоэлектроколориметра с толщиной поглощающего слоя 5 см.

На спектрофотометре SPECORD-M40 провели также измерения оптической плотности исходных растворов и очищенных растворов, отобранных в разное время из верхней части цилиндра после окончания перемешивания. Эффективность очистки оценивали по величинам оптической плотности проб, взятых через 5 минут и через 40 минут отстаивания осадка при $\lambda=250$ нм (по органическим примесям) и $\lambda=670$ нм (по мутности).

Поскольку путем коагуляции не удалось добиться полной очистки от органических примесей, представляло интерес оценить, насколько улучшились биохимические показатели очищенной воды. В серии опытов определили изменение скорости потребления кислорода активным илом в присутствии исходного модельного раствора стока прачечных и раствора, очищенного путем коагуляции с добавками Асканской бентонитовой глины. В работе использовали активный ил, отобранный на Люберецкой станции аэрации г. Москвы, с концентрацией микрофлоры 10 г/дм³ в расчете на сухое вещество.

Образцы исходной и очищенной сточной воды проанализировали по известным методикам [6-8] на содержание анионных и неионогенных ПАВ, общего и органического углерода, остаточного общего железа, взвешенных веществ, сухого и прокаленного остатка, а также ХПК и скорость потребления кислорода активным илом.

\section{Обсуждение результатов}

Результаты экспериментов по изучению сорбции органических примесей на Асканской глине приведены на рис. 1. Опыты показали, что для достижения высокой степени очистки исследуемых стоков с помощью глины требуется длительный период контакта фаз и высокие дозы адсорбента. В то же время следует отметить, что глина обладает неплохой адсорбционной способностью по отношению к органическим загрязнителям, присутствующим в модельном растворе.

На рис. 2 приведены УФ спектры примесей, экстрагированных $\mathrm{CHCl}_{3}$ из исходного модельного раствора (1) и очищенного путем коагуляции (2), подтверждающие присутствие эффекта очистки воды от органических примесей, поглощающих УФ-излучение в интервале исследуемых длин волн светового потока даже при минимальной из изученных дозе глины.

Установлено, что оптимальным временем контакта раствора с глиной является 45 минут: при данном перемешивании в течение этого времени достигается степень очистки 41 отн. \%.

Ход кривых, представленных на рис. 3, показал, что при добавлении сухой глины укрупнение осадка и осветление жидкой фазы происходит с большей скоростью. Увеличение дозы флокулянта вдвое не приводит к повышению скорости осветления жидкости.

Произведенные исследования оптической плотности исходных растворов и очищенных растворов, отобранных в разное время из верхней части цилиндра после окончания перемешивания показали, что добавка сухой глины имеет преимущество в очистке воды как от органических примесей, так и от взвешенных веществ даже в 
первые 5 минут отстаивания осадка. Длительное отстаивание с использованием глинистой суспензии позволяет очистить воду от взвешенных веществ почти на 90 отн.\%, а органические примеси удаляются почти на 56 отн. \%.

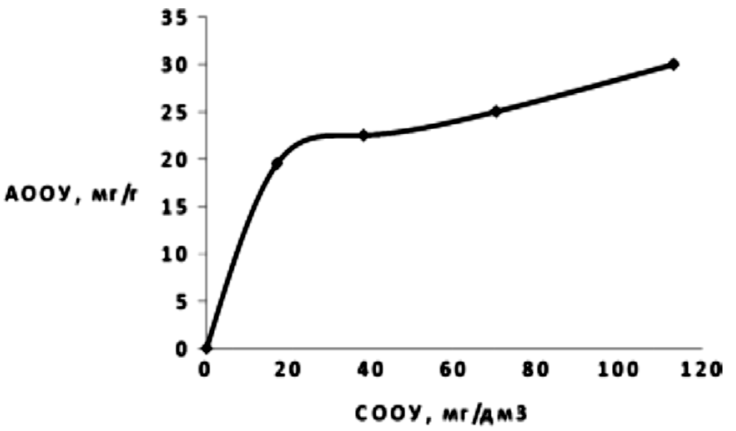

Рис. 1. Изотерма адсорбции органических примесей на Асканской глине (по содержанию ООУ, температура $25^{\circ} \mathrm{C}$. Условия детектирования: хроматограф ЛХМ-8МД, фаза - Полисорб-1, длина колонки 3 м, диаметр колонки 3 мм, чувствительность 3)

Fig. 1. Isotherm of adsorption of organic impurities on Askan clay (by TOC content, temperature $25^{\circ} \mathrm{C}$. Detection conditions: chromatograph LKhM-8MD, phase - Polysorb-1, column length $=3 \mathrm{~m}$, column diameter $=$ $3 \mathrm{~mm}$, sensitivity $=3$ )

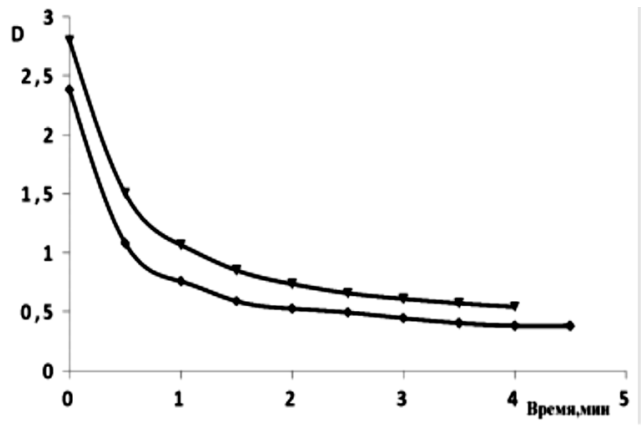

Рис. 2. УФ-спектры экстрактов из образцов исходной и очищенной модельной СВ

(Условия коагуляции: доза Асканской глины 2 г/дм ${ }^{3}$, время перемешивания 15 мин, доза $\mathrm{Fe}^{2+}=100$ мг/дм ${ }^{3}$, доза флокулянта 1.5 мг/дм ${ }^{3}$. Условия определения: спектрофотометр SPECORD-M40, $\delta=2$ мм, растворитель $\mathrm{CHCl}_{3}$, ширина щели 100 , время интегрирования

1 мин, усиление 0 , скорость 0.5 )

Fig. 2. UV-spectra of extracts from samples of the original -־ and purified -

$\boldsymbol{\Delta}$ - model wastewater (Coagulation conditions: Askan clay $=2 \mathrm{~g} / \mathrm{dm}^{3}$, stirring time $=$

$15 \mathrm{~min}, \mathrm{Fe}^{2+}=100 \mathrm{mg} / \mathrm{dm}^{3}$, flocculant $=$ $1.5 \mathrm{mg} / \mathrm{dm}^{3}$. Detection conditions: spectrophotometer SPECORD-M40, $\delta=2 \mathrm{~mm}$, solvent $\mathrm{CHCl}_{3}$, slit width $=100$, integration time $=$ $1 \mathrm{~min}$, gain $=0$, rate $=0.5$ )

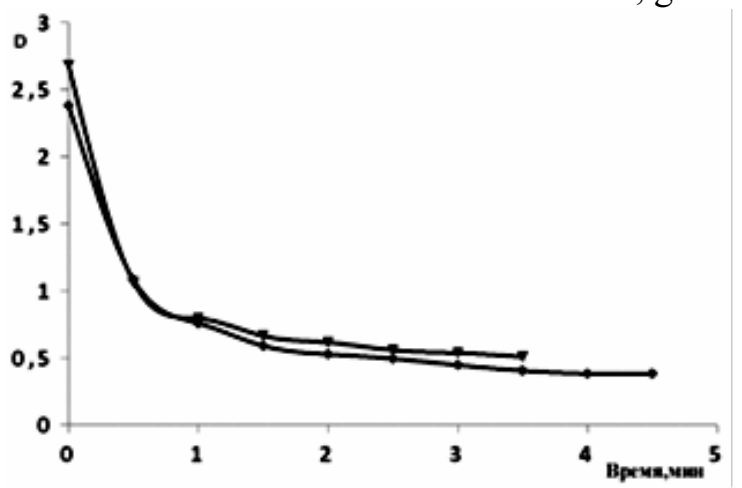

Рис. 3. Влияние предварительного замачивания глины на процесс осветления раствора в процессе коагуляционной очистки модельной СВ (доза Sedipur 1.5 мг/дм ${ }^{3}$ ) Условия опытов: время перемешивания 15 мин, доза глины 2 г/дм д $^{3}$, доза $\mathrm{Fe}^{2+}=100 \mathrm{мг} /$ дм$^{3}$,

КФК-2МП, $\lambda=670 \mathrm{Hм}, \delta=5 \mathrm{~cm}$, высота уровня жидкости в кювете $23 \mathrm{мм})$.

Fig. 3. Influence of preliminary clay soaking on the solution clarification process in the process of coagulation purification of model wastewater (Sedipur $=1.5 \mathrm{mg} / \mathrm{dm}^{3}$ ). Experimental conditions: stirring time $=15 \mathrm{~min}$, clay $=2 \mathrm{~g} / \mathrm{dm}^{3}, \mathrm{Fe}^{2+}=100 \mathrm{mg} / \mathrm{dm}^{3}, \mathrm{KFK}-2 \mathrm{MP}, \lambda=670 \mathrm{~nm}$, $\delta=5 \mathrm{~cm}$, height of the liquid level in the cuvette $=23 \mathrm{~mm}$ ).

Результаты измерений биохимических показателей очищенной воды свиде- 
тельствуют о том, что после коагуляционной очистки резко растет скорость потребления кислорода активным илом, что выражается в увеличении тангенса наклона соответствующей кинетической кривой.

Эндогенное дыхание активного ила $\mathrm{R}_{0}$ составило 0.22 мг $\mathrm{O}_{2} / \Gamma$, для исходного модельного раствора экзогенное дыхание $\mathrm{R}_{э к 3}=0.27$ мг $\mathrm{O}_{2} / \Gamma$, а для очищенного рас-

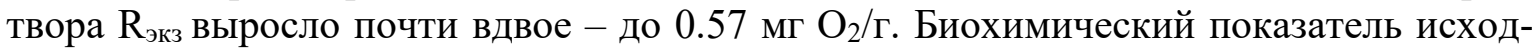
ного раствора $\mathrm{R}_{\text {эк }} / \mathrm{R}_{\mathrm{o}}$ составлял 1.27 , а для очищенного он вырос до 2.59 . Полученные значения говорят о том, что вода, прошедшая коагуляционную очистку с добавками глины, может быть направлена на доочистку на последующей биохимическую ступень после проведения дополнительной операции - окислительной деструкции остаточных органических загрязнителей с помощью пероксида водорода. Результаты анализов на содержание АПАВ, НПАВ, ООУ, ХПК и других показателей приведены в табл. 2. В этой же таблице также содержатся некоторые характеристики осадка, образующегося в процессе коагуляции.

Таблица 2. Основные характеристики исходной и очищенной модельной сточной воды

Table 2. The main characteristics of the original and treated model wastewater

\begin{tabular}{|c|c|c|c|c|}
\hline \multicolumn{5}{|c|}{ Основные характеристики воды } \\
\hline № & Показатели & Исходная & Очищенная & $\alpha, \%$ \\
\hline 1 & $\begin{array}{c}\text { Содержание } \\
\text { АПАВ, мг/дм }\end{array}$ & 83 & 53.6 & 35.4 \\
\hline 2 & $\begin{array}{c}\text { Содержание } \\
\text { НПАВ, мг/дм }\end{array}$ & 62.8 & 44.13 & 29.7 \\
\hline 3 & $\begin{array}{l}\text { Содержание } \\
\text { ООУ, мг/дм }{ }^{3}\end{array}$ & 143.8 & 100.7 & 29.9 \\
\hline 4 & $\begin{array}{c}\text { Содержание } \\
\text { взвешенных ве- } \\
\text { ществ, мг/дм }{ }^{3}\end{array}$ & 204 & 114 & 44.1 \\
\hline 5 & $\begin{array}{l}\text { Химическое по- } \\
\text { требление кис- } \\
\text { лорода, мгО/дм }\end{array}$ & 363.4 & 154 & 57.6 \\
\hline 6 & $\begin{array}{c}\text { Скорость по- } \\
\text { требления кис- } \\
\text { лорода, мг/мин }\end{array}$ & 0.27 & 0.57 & - \\
\hline 7 & $\begin{array}{c}\text { Содержание об- } \\
\text { щего железа, } \\
\text { мг/дм } \text { дм }^{3}\end{array}$ & 100 & 2.4 & \\
\hline 8 & $\begin{array}{c}\text { Масса влажного } \\
\text { осадка, г/дм }\end{array}$ & & 12 & \\
\hline 9 & $\begin{array}{l}\text { Влажность } \\
\text { осадка, \% }\end{array}$ & & 74.2 & \\
\hline 10 & $\begin{array}{l}\text { Масса сухого } \\
\text { осадка, Г/дм }\end{array}$ & & 3.1 & \\
\hline 11 & $\begin{array}{c}\text { Содержание об- } \\
\text { щего железа, } \\
\text { масс.\% в рас- } \\
\text { чете на сухое } \\
\text { вещество }\end{array}$ & & 3.0 & \\
\hline
\end{tabular}

Из полученных данных следует, что в результате коагуляционной очистки со- 
держание АПАВ снизилось на $35.4 \%$ отн., содержание НПАВ - на 29.7\% отн., содержание органического углерода - на 29.9\% отн. Произошла также очистка от взвешенных частиц. Несмотря на добавку глины, их остаточное содержание уменьшилось почти в 2 раза. Следует отметить, что остаточное содержание общего железа в очищен-

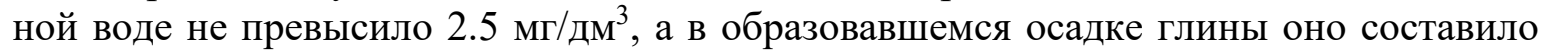
$10 \%$ в расчете на сухое вещество.

\title{
Заключение
}

В результате проведённых исследований авторы показали, что коагуляция с добавками Асканской бентонитовой глины может быть с успехом применена для предварительной очистки стоков прачечных. Образующийся осадок без промежуточной сушки следует утилизировать в технологии углеродминеральных адсорбентов-катализаторов процессов окислительной деструкции органических загрязнений пероксидом водорода. Высокое содержание в нем железа может способствовать активизации процесса окисления.

\section{Список литературы}

1. Кольцова 3.М. Автореферат дисс. канд. техн. наук. М. $1985.16 \mathrm{c}$.

2. Гетманцев С.В., Нечаев И.А., Гандурина Л.В. Очистка производственных сточных вод коагулянтами и флокулянтами. М. «АСВ». 2008,. $271 \mathrm{c}$.

3. Субботкин Л.Д., Вербицкая Н.Ю. // Национальная академия природоохранного и курортного строительства. 2011. Вып. 38. С. 96-106.

4. Павлов Д.В., Вараксин С.О., Колесников В.А. // Водоочистка. 2012. № 4. С. 57-61.

5. Волкова Г.А., Сторожук Н.Ю. // Вестник
Брестского государственного технического университета. Водохозяйственное строительство, теплоэнергетика и геоэкология. 2012. № 2. C. 38-41.

6. Лурье Ю.Ю. Унифицированные методы анализа вод. М. Химия. 1973. 376 с.

7. Штыков С.Н., Сумина Е.Г. Чернова Р.К., Лемешкина Н.В. // Журнал аналитическойхимии. 1985. Т. 40. Вып. 5. С. 907.

8. Перевозчикова Н.Б., Азиатцева Ю.А. // Вестник удмуртского университета. Физика. Химия. 2010. Вып. 2. С. 54-65.

\section{The use of natural montmorillonite clays in the process of coagulation purification of laundry wastewater}

\author{
(C) 2020 Otyrba G.G., Fidchenko M.M., Kamenchuk I.N., \\ Klushin V.N., Kurilkin A.A. \\ D. Mendeleev University of Chemical Technology of Russia, Moscow 125047, Russian Federation
}

A variety of methods, for example, electroflocculation and the same method, complemented by nanofiltration are used for the treatment of wastewater from surface-active substances (surfactants). The authors proposed to use a combination of adsorption and coagulation with a small amount of flocculant to ensure a good cleaning effect from surfactants and suspended substances and reduce costs.

Natural montmorillonite clay from the Askan Deposit (Georgia) was used for the experiments. The model solution of laundry wastewater contained $1 \mathrm{~g} / \mathrm{dm}^{3}$ of both anionic and nonionic surfactants. White kaolin $\left(0.2 \mathrm{~g} / \mathrm{dm}^{3}\right)$ was added to the model solution as a turbidity simulator. Organic impurities were modelled by the addition of sugar $\left(100 \mathrm{mg} / \mathrm{dm}^{3}\right)$. It was shown that a long period of phase contact and a high amount of adsorbent are required in order to achieve a high degree of purification of the studied drains using clay. In the next series of experiments, a coagulant, a solution of $\mathrm{FeCl}_{2}$, flocculant, and clay in the amount of $2 \mathrm{~g} / \mathrm{dm}^{3}$ were 
added to the model solution. The clay additive not only played the role of an effective adsorbent, but also acted as the weighting agent for the coagulant sediment.

The effectiveness of coagulation in combination with clay was evaluated by the residual concentration of total organic carbon (TOC) of the purified solution, the COD of the purified model solution, dried and calcined residue, suspended solids and residual concentration of total iron and the $\mathrm{pH}$ value of the original and purified solutions.

The optimal conditions were: clay $=2 \mathrm{~g} / \mathrm{dm}^{3}, \mathrm{Fe}^{2+}=100 \mathrm{mg} / \mathrm{dm}^{3}$, flocculant $=1.5 \mathrm{mg} / \mathrm{dm}^{3}$, and a settling time of 5 minutes. When stirring for 45 minutes, the degree of purification was 41 Rel. \%. When comparing the use of dry bentonite clay and its $10 \%$ suspension in water, it was found that when adding dry clay, the sediment enlargement and clarification of the liquid phase occured at a higher rate, and the purification from organic impurities reached 56 Rel.\% and suspended substances reached 90 Rel. \%.

Based on the conducted research, we can conclude that coagulation with additives of Askan bentonite clay is successful for pre-treatment of laundry drains with the possibility of recycling the resulting sludge without intermediate drying by the carbon-mineral adsorbents-catalysts technology.

Keywords: water purification from organic impurities, coagulation, suspended substances, surfaceactive substances, laundry drains, bentonite clay.

\section{References}

1. Kol'cova Z.M. Avtoreferat diss. cand. teh. Hauk., M., 1985, 16 p.

2. Getmancev S.V., Nechaev I.A., Gandurina L.V. Ochistka proizvodstvennyh stochnyh vod koaguljantami i flokuljantami. Moscow, «ASV», 2008, 271 p.

3. Subbotkin L.D., Verbickaja N.Ju., Nacional'naja akademija prirodoohrannogo $i \mathrm{ku}$ rortnogo stroitel'stva, 2011, Is. 38, pp. 96-106.

4. Pavlov D.V., Varaksin S.O., Kolesnikov V.A., Vodoochistka, 2012, No 4, pp. 57-61.

5. Volkova G.A., Storozhuk N.Ju., Vestnik Brestskogo gosudarstvennogo tehnicheskogo

Отырба Гудиса Геннадьевич - магистрант кафедры Промышленной экологии, РХТУ им. Менделеева, Москва

Фидченко Михаил Михайлович - аспирант кафедры Технологии неорганических веществ и электрохимических производств, РХТУ им. Менделеева, Москва

Клушин Виталий Николаевич - д.т.н., профессор кафедры Промышленной экологии, РХТУ им. Менделеева, Москва

Каменчук Ирина Николаевна - к.т.н., инженер кафедры Промышленной экологии, РХТУ им. Менделеева, Москва

Курилкин Александр Александрович к.т.н., инженер кафедры Промышленной экологии, РХТУ им. Менделеева, Москва universiteta. Vodohozjajstvennoe stroitel'stvo, teplojenergetika i geojekologija, 2012, No 2, pp. $38-41$.

6. Unificirovannye metody analiza vod. izd. 2, ispr., pod red. d-ra him. nauk Ju.Ju.Lur'e. M., Chemistry, 1973, 376 p.

7. Shtykov S.N., Sumina E.G. Chernova R.K., Lemeshkina N.V., Zhurnal analiticheskoj khimii, 1985, Vol. 40, Issue. 5. P. 907.

8. Perevozchikova N.B., Aziatceva Ju.A., Vestnik udmurtskogo universiteta. Fizika. Khimija, 2010, Issue. 2, pp. 54-65.

Otirba Gudisa G. - undergraduate of department of Industrial Ecology, MUCTR, Moscow

Fidchenko Mikhail M. - postgraduate of departament of Inorganic Substances and Electrochemical Production engineering, MUCTR, Moscow

Klushin Vitaly N. - grand $\mathrm{PhD}$ (engineering), professor of department of Industrial Ecology, MUCTR, Moscow

Kamenchuk Irina N. - PhD in engineering, engineer of department of Industrial Ecology, MUCTR, Moscow, E-mail: kamenc-irina@yandex.ru

Kurilkin Alexander A. - PhD in engineering, engineer of department of Industrial Ecology, MUCTR, Moscow, E-mail: akurilkin85@gmail.com 